\title{
A Heat Load Distribution Method for Retrofitting Heat Exchanger Networks
}

\author{
Hür Bütün ${ }^{\mathrm{a}^{*}}$, Ivan Kantor $^{\mathrm{a}}$, Alberto Mian $^{\mathrm{a}}$ and François Maréchal ${ }^{\mathrm{a}}$ \\ ${ }^{a}$ École Polytechnique Fédérale de Lausanne, IPESE, Sion, Switzerland \\ hur.butun@epfl.ch
}

\begin{abstract}
Fluctuating energy prices, increasing environmental concerns, and regulations push industries toward more energy efficient plants. Process integration (PI) techniques, proven to be effective in providing solutions with improved energy and material efficiencies often neglect modifications to the heat exchanger network (HEN). HEN design methods have been studied extensively to overcome this drawback of process integration but often still focus on grassroots design to suggest retrofits. This work proposes a method to solve heat load distribution (HLD), a sub problem of HEN design, in the context of retrofit problems. The problem is solved using a mixed integer linear programming (MILP) model with integer cuts (IC) to obtain many retrofit options with high computational speed. The model is built on previously developed methods for PI (Marechal and Kalitventzeff, 2003) and HEN design (Ciric and Floudas, 1989; Mian et al., 2016), such as mathematical programming (MP) and pinch analysis (PA). The objective function of the proposed method is minimisation of the estimated cost of the modifications required in an existing HEN, by considering the costs of repiping, additional heat exchanger area and additional heat exchangers. The estimated area of the potential stream matches is calculated using graphical techniques on the process integration results and taking into account correction factor. The additional heat exchanger area is constrained to practical limits available in the literature. The cost of heat exchanger area is calculated using piece-wise linearization of nonlinear cost functions. Solving the model yields information on stream matches and their heat loads as well as identifying which streams should be repiped and which heat exchangers should be modified or replaced. An industrial case study is solved to show the effectiveness of the proposed method resulting in annualized cost reductions of $9 \%$ considering the HEN design alone and $29 \%$ with modifications to the utility system to include heat pumping.
\end{abstract}

Keywords: process integration, heat exchanger network, retrofit, heat load distribution

\section{Introduction}

Industrial energy consumption represents $26 \%$ of the European total; industry is therefore incentivized by regulatory bodies to improve energy efficiency. Improving energy efficiency in industry has thus been a primary concern in research studies. PI techniques emerged after the oil crisis in 1970s and are still relevant and effective energy targeting methods to solve industrial energy efficiency problems (Klemeš and Kravanja, 2013). PI results typically propose solutions that require modifications to existing plants. Although investment in new technologies and equipment is considered with PI techniques, heat exchanger modifications are typically neglected. Several methods are available to include the cost of the modifications in the heat exchangers within PI (Bütün et al., 2017) or as post-processing (Ahmad et al., 1990). However, without knowing the 
HEN superstructure or even the stream matches, estimation from these methods might deviate significantly from the real cost. HEN design has been deeply studied to improve calculation of the total cost of energy saving measures.

Yee and Grossmann (1990) proposed the SYNHEAT model using mixed integer non-linear programming (MINLP) to solve energy targeting, the matches between hot and cold streams and the optimal superstructure of the HEN simultaneously. One of the nonlinear constraints in HEN is calculation of logarithmic mean temperature difference (LMTD). Barbaro and Bagajewicz (2005) eliminated the nonlinear LMTD constraints by using fixed temperature intervals and formulated the HEN problem in the form of MILP by using linear cost functions.

Since heat exchanger network design is a difficult problem to solve, decomposition methods for dividing and solving it as several subproblems have been developed. The most common three subproblems of HEN are energy targeting (i.e. energy integration) (Papoulias and Grossmann, 1983), minimum number of hot-cold stream matches (i.e. HLD) (Cerda and Westerburg, 1983) and minimum heat exchanger area cost (i.e. HEN superstructure) (Floudas and Grossmann, 1987). François and Irsia (1989) proposed the SYNEP model which solves the heat exchanger network subproblems by including heuristics. Mian et al. (2016) improved the heat exchanger network superstructure by allowing both parallel and series configurations and coupled MP methods with particle swarm optimization.

Retrofitting problems are currently the focus of many European industries since energy efficiency improvements are implemented on existing sites. Ciric and Floudas (1989) proposed a method to solve the HLD subproblem by including retrofit constraints. Afterward, a MINLP model formulation (Ciric and Floudas, 1990) was used to find the optimal retrofit superstructure applying an iterative procedure. Nguyen et al. (2010) proposed a MILP formulation using the fixed temperature interval model of Barbaro and Bagajewicz (2005).

A gap is identified for solving the HLD in retrofit situations since existing methods either do not clearly state how LMTD is calculated (Ciric and Floudas, 1989) or use predefined temperature intervals and linear cost functions (Barbaro and Bagajewicz, 2005) to fit within the MILP domain. This paper proposes a method to solve HLD retrofit problems based on the work of Ciric and Floudas (1989). The results of HLD can be used for heat exchanger network design in case of unsplit acyclic HENs as suggested by Cerda and Westerburg (1983) or can be followed by superstructure synthesis.

\section{Methodology}

\subsection{Energy integration}

The energy integration (i.e. targeting) subproblem must be solved prior to considering HLD. The problem is defined with a set of units $(\mathbf{U})$ consisting of the set of process units (PU) with fixed sizes and utility units (UU) which are scheduled using binary variables $(y)$ and sized using continuous variables $(f)$. The energy and material flows are modelled as thermal and mass streams with set of streams $(\mathbf{S})$. Streams are assigned to units such that sizing and scheduling agree with their containing units. The details of the MILP formulation of energy integration can be found in Marechal and Kalitventzeff (2003).

\subsection{LMTD calculation from graphical methods}

LMTD evaluation is nonlinear and hence cannot be calculated within an MILP. One novelty this paper brings is the LMTD estimation at the level of HLD. The method to obtain vertical segments from the composite curves (Ahmad et al., 1990) is adapted. This way the LMTD for each vertical zone in the composite curve can be obtained. However, HLD is formulated with temperature 
intervals. The $\mathrm{LMTD}_{i j k}$ of the hot $(\mathrm{i} \in \mathbf{H})$ and cold $(\mathrm{j} \in \mathbf{C})$ streams in each temperature interval $(\mathrm{k} \in \mathbf{K})$ is calculated by taking the weighted average of the LMTD of the vertical segments in the temperature interval. Afterwards, this parameter is used to calculate the area required for the heat transfer of the match i-j using Eqns. (1) and (2).

$$
\begin{aligned}
& A_{i j k}=\frac{\dot{Q}_{i j k}}{\mathrm{U}_{i j k} \cdot \mathrm{LMTD}_{i j k} \cdot \mathrm{F}_{c o r r}} \quad \forall i \in \mathbf{H}, j \in \mathbf{C}, k \in \mathbf{K} \\
& A_{i j}=\sum_{z=1}^{\mathbf{K}} A_{i j k} \quad \forall i \in \mathbf{H}, j \in \mathbf{C}
\end{aligned}
$$

\subsection{Heat load distribution for retrofitting}

The HLD problem is defined from the results of energy integration (EI). The units that are not used in EI are removed from the set of units for HLD. Since HLD focuses on heat, it only considers thermal streams from the overall set of streams. The unit sizes and hence the heat load of the streams are fixed as parameters. The existing heat exchangers in the system are defined as a set $(\mathbf{X})$. To model the stream segments, the set of stream groups (SG) is used. As such, when a stream with phase change or varying heat capacity is defined, a stream for each segment is created but all are assigned to the same stream group. Stream groups are then separated into the set of hot stream groups (HG) and the set of cold stream groups (CG). The matches are created between $\mathrm{i}$ $\in \mathbf{H G}$ and $\mathbf{j} \in \mathbf{C G}$ using binary variables $\left(y_{i j}\right)$. The problem size is therefore greatly reduced in problems with segmented streams compared to existing methods available in literature. The heat load of the stream matches is determined using the heat flow model presented by (Floudas et al., 1986). Modifications in the existing heat exchanger network are classified into six categories as proposed by (Ciric and Floudas, 1989). Each stream pair in the solution can be defined according to the required modifications, or lack thereof.

- Category 1: No modification, no cost. The existing stream match is housed in the current heat exchanger. Hence, no modification is required. The matches are assigned to this category using set $\mathbf{C 1}$

- Category 2: Moving the heat exchanger. The existing stream match is housed in an existing exchanger, though not the one currently employed for this purpose. Hence, this category requires moving the heat exchanger. The matches are assigned to this category using set $\mathbf{C 2}$

- Category 3: Repiping one stream. A new match is housed in a heat exchanger from the existing network which was housing either the cold or the hot stream of the match. The matches are assigned to this category using set $\mathbf{C 3}$

- Category 4: Repiping two streams. A new match is housed in a heat exchanger from the existing network which had no connection with either the cold or hot stream of current network.The matches are assigned to this category using set $\mathbf{C 4}$

- Category 5: Purchasing a new heat exchanger. An existing stream match is housed in a new heat exchanger. The matches are assigned to this category using set $\mathbf{C 5}$

- Category 6: Purchasing a new heat exchanger and repiping. A new stream match is housed in a new heat exchanger. The stream matches are assigned to this category using set $\mathbf{C 6}$

In contrast to the methods available in literature, only the matches that include at least one stream group from a process unit are considered for the listed retrofitting categories. This approach omits the cost of heat exchangers between utility units (e.g. boiler and steam network), thus only optimising interactions which affect the process units.

The cost of modifications according to the retrofitting categories can be summarised as moving a heat exchanger, repiping stream(s) and purchasing a new heat exchanger. In addition, when one of the heat exchangers from the existing networks is reused, its area can be increased (i.e. additional heat exchanger area). The cost of moving heat exchangers, repiping and additional 
heat exchanger area are calculated using linear formulas found in Rezaei and Shafiei (2009). Cost calculation for new heat exchangers is completed by applying piece-wise linearization to nonlinear cost estimation formulae. The objective Eqn. (3) is minimization of the total modification cost required in the network.

$$
\begin{aligned}
\min _{y, n, A} & \sum^{\mathbf{C} 2} y_{i j x} \cdot \mathrm{c}^{\text {move }}+\sum^{\mathbf{C} 3} y_{i j x} \cdot \mathrm{c}^{\text {rep } 1}+\sum^{\mathbf{C} 4} y_{i j x} \cdot \mathrm{c}^{\text {rep2 } 2} \\
& +\sum^{\mathbf{C 5}}\left(n_{i j} \cdot \mathrm{c}^{i n s t}+A_{i j}^{\text {purc }}\right)+\sum^{\mathbf{C 6}}\left(n_{i j} \cdot \mathrm{c}^{i n s t+r e p 2}+A_{i j}^{\text {purc }}\right)+\sum^{\mathbf{X}} A_{i j x}^{\text {add }}
\end{aligned}
$$

The retrofit constraints are given in Eqns. (4) to (8). An existing heat exchanger is assigned to maximum one stream match by Eqn. (4). Each match is assigned to either an existing heat exchanger or a new one by Eqn. (5). Heat exchanger area required for each match must be equal to the heat exchanger area used from the existing exchangers and the new heat exchanger area using Eqn. (6). The new heat exchanger area assigned to a stream match is equal to either heat exchanger area added to an existing exchanger or the area of a purchased heat exchanger (i.e. a new heat exchanger) by Eqn. (7). The additional area to the existing heat exchangers is constrained to the practical limits by Eqn. (8). The heat flow model and the equations concerning stream matches can be found in Mian et al. (2016). Tbl. 1 depicts the description of the symbols used in the formulation.

$$
\begin{aligned}
& \sum_{i=1}^{\mathbf{H G}} \sum_{j=1}^{\mathbf{C G}} y_{i j x} \leq 1 \quad \forall x \in \mathbf{X} \\
& y_{i j x}+n_{i j}-y_{i j}=0 \quad \forall i \in \mathbf{H G}, j \in \mathbf{C G}, x \in \mathbf{X} \\
& A_{i j}^{\text {new }}+A_{i j x}^{\text {exist }}-A_{i j}=0 \quad \forall i \in \mathbf{H G}, j \in \mathbf{C G}, x \in \mathbf{X} \\
& A_{i j}^{\text {new }}=A_{i j x}^{\text {add }}+A_{i j}^{\text {purc }} \quad \forall i \in \mathbf{H G}, j \in \mathbf{C G}, x \in \mathbf{X} \\
& A_{i j x}^{\text {add }} \leq A_{i j x}^{\text {exist }} \cdot \operatorname{add}^{\text {max }} \quad \forall i \in \mathbf{H G}, j \in \mathbf{C G}, x \in \mathbf{X}
\end{aligned}
$$

Table 1: Description of the symbols in the formulation

\begin{tabular}{clcl}
\hline Symbol & Description & Symbol & Description \\
\hline$y$ & Binary to decide a stream match & exist & Existing \\
$n$ & Binary to decide a new stream match & add & Additional \\
$A$ & Area of the stream match & purc & Purchase \\
$\dot{Q}$ & Heat load & move & Moving \\
$\tilde{U}$ & Overall heat transfer coefficient & rep1 & Repiping 1 stream \\
$F_{\text {corr }}$ & LMTD correction factor & rep2 & Repiping 2 streams \\
$c$ & Specific cost & inst & Installation \\
\hline
\end{tabular}

\section{Case Study}

An industrial production plant is studied to apply the proposed method. In the current state of the site, heat recovery between hot and cold processes is not applied. Therefore, all process heating requirements are supplied by the heating utilities and hot processes are cooled by cooling utilities. The existing plant uses a boiler to provide heating which is distributed to processes through the steam network. Air and water heat exchangers are both used to supply the process cooling requirements. The list of process streams, their current stream matches and and heat exchanger area are given in Tbl. 2.

In addition to the existing utilities, integration of two heat pumps is considered. The evaporation and condensation temperature levels of the heat pumps are decided based on the grand composite curve (GCC) of the plant. 
Table 2: Streams and initial heat exchanger areas of the case study

\begin{tabular}{lccccccccccc}
\hline Stream & $\begin{array}{c}\mathrm{T}_{\text {in }} \\
{\left[{ }^{\circ} \mathrm{C}\right]}\end{array}$ & $\begin{array}{c}\mathrm{T}_{\text {out }}\left[\begin{array}{c}\left.{ }^{\circ} \mathrm{C}\right] \\
\text { sat }\end{array}\right. \\
{\left[{ }^{\circ} \mathrm{C}\right]}\end{array}$ & $\begin{array}{c}\Delta \mathrm{Q} \\
{[\mathrm{kW}]}\end{array}$ & $\begin{array}{c}\text { Area } \\
{\left[\mathrm{m}^{2}\right]}\end{array}$ & Stream & $\begin{array}{c}\mathrm{T}_{\text {in }} \\
{\left[{ }^{\circ} \mathrm{C}\right]}\end{array}$ & $\begin{array}{c}\mathrm{T}_{\text {out }} \\
{\left[{ }^{\circ} \mathrm{C}\right]}\end{array}$ & $\begin{array}{c}\mathrm{T}_{\text {sat }} \\
{\left[{ }^{\circ} \mathrm{C}\right]}\end{array}$ & $\begin{array}{c}\Delta \mathrm{Q} \\
{[\mathrm{kW}]}\end{array}$ & $\begin{array}{c}\text { Area } \\
{\left[\mathrm{m}^{2}\right]}\end{array}$ \\
\hline $\mathrm{C} 1$ & 51 & 56 & 56 & 404 & 5.5 & $\mathrm{H} 4$ & 55 & 33 & - & 1150 & 121.2 \\
$\mathrm{C} 2$ & 79 & 84 & 84 & 2172 & 35.5 & $\mathrm{H} 5$ & 44 & 31 & - & 246 & 34.9 \\
$\mathrm{C} 3$ & 61 & 66 & 66 & 284 & 4.1 & $\mathrm{H6}$ & 47 & 40 & - & 144 & 19.5 \\
$\mathrm{C} 4$ & 58 & 63 & 63 & 1894 & 26.9 & $\mathrm{H7}$ & 67 & 35 & 67 & 1340 & 475 \\
$\mathrm{C} 5$ & 60 & 65 & 65 & 1960 & 41.6 & $\mathrm{H} 8$ & 86 & 35 & 86 & 1172 & 304.7 \\
$\mathrm{C} 6$ & 43 & 100 & 100 & 1974 & 61.3 & $\mathrm{H} 9$ & 57 & 35 & 57 & 2488 & 1095.5 \\
$\mathrm{C} 7$ & 43 & 100 & 100 & 824 & 25.6 & $\mathrm{H} 10$ & 67 & 35 & 67 & 1286 & 451.9 \\
$\mathrm{C} 8$ & 63 & 68 & 68 & 1442 & 31.5 & $\mathrm{H} 11$ & 67 & 31 & 67 & 780 & 283.1 \\
$\mathrm{C} 9$ & 53 & 58 & 58 & 420 & 8.4 & $\mathrm{H} 12$ & 69 & 35 & 69 & 2256 & 776.9 \\
$\mathrm{H} 1$ & 53 & 31 & - & 610 & 70.4 & $\mathrm{H} 13$ & 177 & 40 & 61 & 2574 & 806.9 \\
$\mathrm{H} 2$ & 50 & 38 & - & 46 & 44.7 & $\mathrm{H} 14$ & 81 & 39 & 81 & 730 & 195.6 \\
$\mathrm{H} 3$ & 41 & 32 & - & 2218 & 332.8 & $\mathrm{H} 15$ & 58 & 35 & - & 680 & 431 \\
\hline
\end{tabular}

\section{Results and discussion}

The current energy bill of the plant is calculated to represent the base case scenario (BCS) and hence provide a basis of comparison for benefits of the energy saving solutions. EI is carried out in several scenarios. energy saving scenario 1 (ES1) presents a scenario where investment in new energy conversion technologies is not desired. Improvements in energy efficiency must therefore be through better use of the resources and systems available on the plant. In energy saving scenario 2 (ES2), integration of heat pumps is also considered.

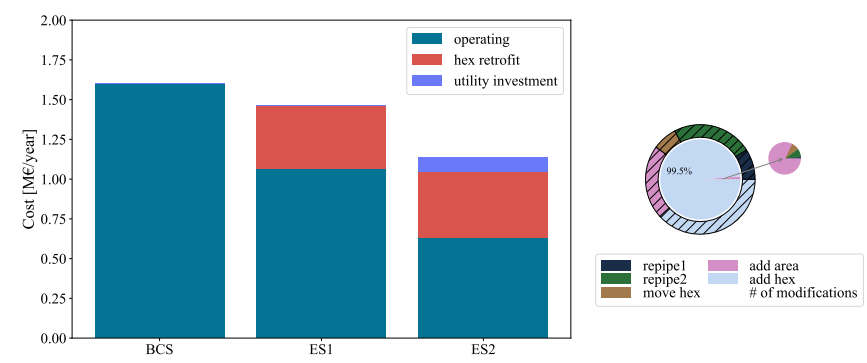

Figure 1: Cost comparison of scenarios (left), distribution modifications in ES2 (right)

EI is followed by HLD retrofit optimization for each scenario (excluding the base case) which yields cost estimation of the heat exchanger network modifications to achieve the improvements in energy efficiency. In Fig. 1 the comparison of the base case and energy saving scenarios can be seen. Operating cost is reduced by $33 \%$ with more efficient use of the steam network and another $28 \%$ with the integration of heat pumps. When the cost of the modifications estimated by HLD and the cost of the heat pumps are considered, the reduction in the total cost becomes 9\% and 29\% in ES1 and ES2, respectively. The details of heat exchanger network modifications for ES2 are given in Fig. 1. The number of modifications of each type can be seen in the outer pie chart while the distribution of the cost of the modifications is plotted in the inner chart. The cost of the modifications is dominated by the cost of new heat exchangers added to the network. Since the remaining contributions are marginal, the distribution of cost amongst them is plotted separately. The cost of adding area to the existing heat exchangers has the largest cost contribution. One reason for this distribution is that repiping and moving heat exchangers have unit cost per modification while additional heat exchanger area also depends on the size of the modification.

In HLD, because of the nature of the problem, the same or similar objective function evaluations with different configurations. In industrial applications, these alternatives are important to provide several options for improvement since not all constraints are accounted for in the formulation of the optimization. IC is applied to the HLD retrofit of ES2. The comparison of IC scenarios is depicted inFig. 2. With the integer cut solutions, ten different modification combinations are proposed, with objective values within $1 \%$ of the optimal. 


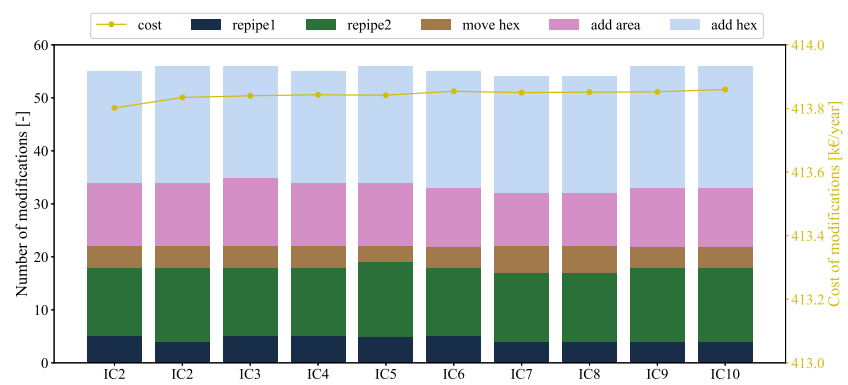

Figure 2: Integer cuts results

\section{Conclusion}

In this work, a mathematical programming method is proposed to solve HLD in the context of retrofit problems. The categories of modifications are defined as moving heat exchangers, repiping stream(s) of an existing heat exchanger, adding heat exchanger area to the existing heat exchangers and adding new heat exchangers. The method is applied to a real industrial problem where the total cost of the system was reduced by $29 \%$ considering integration of new utilities, more efficient use of the existing ones and the estimated cost of the modifications in the heat exchanger network. Multiple options for retrofitting were obtained by applying integer cuts in HLD. The method can be used to make preliminary retrofit decisions as well as to determine the stream matches prior to HEN superstructure synthesis.

\section{Acknowledgements}

This project has received funding from the European Union's Horizon 2020 research and innovation programme under grant agreement No 679386.

\section{References}

Ahmad, S., Linnhoff, B., Smith, R., Jul. 1990. Cost optimum heat exchanger networks—2. targets and design for detailed capital cost models. Computers \& Chemical Engineering 14 (7), 751-767.

Barbaro, A., Bagajewicz, M. J., Aug. 2005. New rigorous one-step MILP formulation for heat exchanger network synthesis. Computers \& Chemical Engineering 29 (9), 1945-1976.

Bütün, H. E., Kantor, I. D., Maréchal, F., 2017. A process integration method with multiple heat exchange interfaces. Proceedings of ECOS 2017, 1447-1460.

Cerda, J., Westerburg, A. W., 1983. Synthesizing Heat Exchanger Networks Having Restricted Stream/Stream Matches Using a Transportation Problem Formulation. Chemical Engineering Science 38 (10), 1723-1740.

Ciric, A., Floudas, C., Jun. 1989. A retrofit approach for heat exchanger networks. Computers \& Chemical Engineering 13 (6), 703-715.

Ciric, A. R., Floudas, C. A., Feb. 1990. A mixed integer nonlinear programming model for retrofitting heat-exchanger networks. Industrial \& Engineering Chemistry Research 29 (2), 239-251.

Floudas, C. A., Ciric, A. R., Grossmann, I. E., Feb. 1986. Automatic synthesis of optimum heat exchanger network configurations. AIChE Journal 32 (2), 276-290.

Floudas, C. A., Grossmann, I. E., Jan. 1987. Automatic generation of multiperiod heat exchanger network configurations. Computers \& Chemical Engineering 11 (2), 123-142.

François, M., Irsia, B., Apr. 1989. Synep1 : A methodology for energy integration and optimal heat exchanger network synthesis. Computers \& Chemical Engineering 13 (4-5), 603-610.

Klemeš, J. J., Kravanja, Z., Nov. 2013. Forty years of Heat Integration: Pinch Analysis (PA) and Mathematical Programming (MP). Current Opinion in Chemical Engineering 2 (4), 461-474.

Marechal, F., Kalitventzeff, B., Oct. 2003. Targeting the integration of multi-period utility systems for site scale process integration. Applied Thermal Engineering 23 (14), 1763-1784.

Mian, A., Martelli, E., Maréchal, F., Jan. 2016. Framework for the Multiperiod Sequential Synthesis of Heat Exchanger Networks with Selection, Design, and Scheduling of Multiple Utilities. Industrial \& Engineering Chemistry Research 55 (1), 168-186.

Nguyen, D. Q., Barbaro, A., Vipanurat, N., Bagajewicz, M. J., Jul. 2010. All-At-Once and Step-Wise Detailed Retrofit of Heat Exchanger Networks Using an MILP Model. Industrial \& Engineering Chemistry Research 49 (13), 6080_ 6103. 
Papoulias, S. A., Grossmann, I. E., Jan. 1983. A structural optimization approach in process synthesis-II. Computers \& Chemical Engineering 7 (6), 707-721.

Rezaei, E., Shafiei, S., Sep. 2009. Heat exchanger networks retrofit by coupling genetic algorithm with NLP and ILP methods. Computers \& Chemical Engineering 33 (9), 1451-1459.

Yee, T., Grossmann, I., Oct. 1990. Simultaneous optimization models for heat integration-II. Heat exchanger network synthesis. Computers \& Chemical Engineering 14 (10), 1165-1184. 